\title{
Deep ocean inertia-gravity waves simulated in a high-resolution global coupled atmosphere-ocean GCM
}

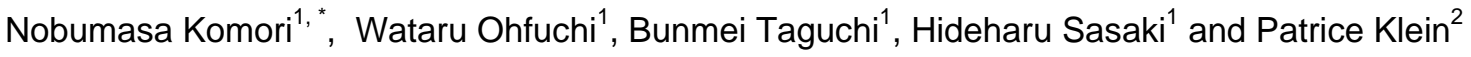 \\ ${ }^{1}$ Earth Simulator Center, Japan Agency for Marine-Earth Science and Technology, Yokohama, Japan. \\ ${ }^{2}$ Laboratoire de Physique des Océans, IFREMER, Plouzané, France. \\ *: Corresponding author : N. Komori, email address : komori@jamstec.go.jp
}

\begin{abstract}
:
In order to investigate the deep ocean inertia-gravity waves, a high-resolution global coupled atmosphere-ocean simulation is carried out with a coupling interval of 20 minutes. Large ( $10-3 \mathrm{~m}$ $\mathrm{s}-1$ ) root-mean-square variability of vertical velocity is found in middepths $(2000-4000 \mathrm{~m})$, which is not reported in previous studies using realistic ocean simulations. Horizontal distribution of the large variability roughly corresponds to the wintertime atmospheric storm tracks and is stretched equatorward due to $\beta$-dispersion in open ocean with some "shadow regions" behind the obstacles. Frequency spectrum of vertical velocity has strong peaks at around $f$ and $2 f$ ( $f$ is the local inertial period) in midlatitudes, and has additional peak at around (3/2)f or $3 f$ at some points. These results suggest necessity of re-evaluation of wind-induced near-inertial energy with high-frequency atmospheric forcing.
\end{abstract}

Keywords: inertia-gravity wave; deep ocean; coupled atmosphere-ocean model. 


\section{Introduction}


to wintertime atmospheric disturbances with focusing on its vertical velocity, the latter being easily distinguished from the background flow field without any a priori filtering, because of its energy peaks at inertial frequencies.

\section{Model and Data}

We have carried out a global coupled atmosphere-ocean simulation using CFES [Komori et al., 2007], which consists of AFES [Ohfuchi et al., 2004; Enomoto et al., 2007] as the atmospheric component and OFES [Masumoto et al., 2004; Komori et al., 2005] as the oceanic component. The latter is based on GFDL MOM 3 [Pacanowski and Griffies, 1999]. The main advantage of using a coupled model is that its resolution allows to take into account of the wind intermittency that drives the generation of ocean inertial waves.

The resolution of the atmospheric component is T239 (the triangle truncation at wave number 239, $\sim 50 \mathrm{~km}$ ) in horizontal and 48 layers in vertical. The horizontal resolution of the oceanic component is $1 / 4^{\circ}(\sim 25 \mathrm{~km}$ at the equator) in both longitude and latitude, and there are 54 levels in vertical, with varying distance between the levels from $5 \mathrm{~m}$ at the surface to $330 \mathrm{~m}$ at the maximum depth of $6065 \mathrm{~m}$. For the horizontal mixing of momentum and tracers, biharmonic operator is applied with viscosity $A_{0} \cos ^{3} \phi$ and diffusivity $K_{0} \cos ^{3} \phi$, where $A_{0}=27.0 \times 10^{10}$ $\mathrm{m}^{4} \mathrm{~s}^{-1}, K_{0}=9.0 \times 10^{10} \mathrm{~m}^{4} \mathrm{~s}^{-1}$, and $\phi$ is latitude. For the vertical mixing, the KPP scheme [Large et al., 1994] is employed with background viscosity and diffusivity of $1.0 \times 10^{-4}$ and $0.1 \times 10^{-4}$ $\mathrm{m}^{2} \mathrm{~s}^{-1}$, respectively. Coupling quantities (ocean surface variables for the atmospheric component; sea level pressure and momentum, heat, and freshwater fluxes for the oceanic component) are updated every 20 minutes, which is short enough to resolve the intermittent atmospheric disturbances. 
After five-year coupled spin-up integration, vertical velocity, $w$, of the world ocean is sampled every hour for one month from 00:30UTC of January 1.

\section{Results}

Figure 1 shows snapshots of $w$ at 2012-m depth in the North Pacific and in the North Atlantic. The amplitude reaches $100 \mathrm{~m} \mathrm{day}^{-1}$ in both basin and exceeds $200 \mathrm{~m} \mathrm{day}^{-1}$ in some area. Striped pattern of $w$ is formed especially in the interior regions and propagates equatorward due to $\beta$ dispersion [Anderson and Gill, 1979; Nagasawa et al., 2000; Garrett, 2001]. The meridional wavelength is about $200 \mathrm{~km}$ in midlatitudes and becomes shorter in lower latitudes as expected from the effect [D'Asaro et al., 1995]. In the Kuroshio Extension and Gulf Stream regions $w$ is a little smaller than further east and less organized. Such regions correspond to those where the mixed layer depth is large in our simulation result (not shown), which potentially leads reduction of wind-induced energy input there [Watanabe and Hibiya, 2002]. The presence in the western part of mesoscale eddies (although not well resolved) and complicated bathymetry should make the inertial motions to be less organized than in the eastern part where only the $\beta$-effect is present.

The root-mean-square (RMS) variability of $w$ at 2012-m depth in the world ocean is shown in Fig. 2. RMS variability of the surface stress (wind stress for open ocean and ocean-ice stress for ice-covered region) magnitude is also plotted in the figure. The value of RMS variability of $w$ is beyond $10^{-3} \mathrm{~m} \mathrm{~s}^{-1}$ in the central and eastern North Pacific in midlatitudes at this depth. Horizontal distribution of large RMS variability of $w$ roughly corresponds to the distribution of large variability of surface stress and to the estimated distributions of large wind-induced energy input [Alford, 2001, 2003; Watanabe and Hibiya, 2002], that is, there are strong maxima 
has strong and broad peaks at around $f$ and $2 f$ and a weak peak at around $(3 / 2) f(\sim 0.08 \mathrm{cph})$ in the deep layer. Note that a weak peak at this frequency in the deep layer is also found in frequency spectrum at $45.1^{\circ} \mathrm{N}$ (Fig. 4a) as well as peaks at around $f$ and $2 f$. The $f$ and $2 f$ peaks are easily found at other locations in midlatitude, whereas the $(3 / 2) f$ and $3 f$ peaks are seldom found. At lower latitude (Fig. 4d), frequency spectrum becomes much broader.

\section{Possible Mechanism}

The idealized numerical experiments [Price, 1983; Niwa and Hibiya, 1997] showed that super-inertial ( $2 f$ and $3 f$ ) waves are excited as lee waves by traveling storms/hurricanes over the ocean. Niwa and Hibiya [1997] suggested that the lowest-vertical-mode double-inertial wave is generated through the nonlinear interaction between the high-vertical-mode near-inertial waves. Danioux and Klein [2007] proposed another mechanism, a scale-selective resonance which is activated by oceanic mesoscale structure and produces dominant frequency-wavenumber pairs such as $(2 f, \sqrt{3} / r)$ and $(3 f, \sqrt{8} / r)$ with $r$ the Rossby radius of deformation of each vertical mode. These two results are extremes in a sense that Niwa and Hibiya [1997] does not consider the oceanic horizontal structure and Danioux and Klein [2007] does not consider the movement of wind forcing. Detailed analysis using vertical normal modes will help to understand the mechanism which induces super-inertial waves in middepths as well as the double-peaked vertical profile of RMS variability of $w$, but this remains for future work.

\section{Concluding Remarks}

A high-resolution global coupled atmosphere-ocean simulation is carried out to investigate the deep ocean inertia-gravity waves. It is found that RMS variability of $w$ is large $\left(\sim 10^{-3}\right.$ $\mathrm{m} \mathrm{s}^{-1}$ ) in middepths (2000-4000 m), and its frequency spectrum has strong peaks at around $f$ 
Kuwano-Yoshida. Nobumasa Komori is partly supported by Grant-in-Aid for Scientific Research (19340130) from MEXT of Japan. The numerical calculation was carried out on the Earth Simulator under support of JAMSTEC.

\section{References}

Alford, M. H. (2001), Internal swell generation: The spatial distribution of energy flux from the wind to mixed layer near-inertial motions, J. Phys. Oceanogr., 31(8), 2359-2368.

Alford, M. H. (2003), Improved global maps and 54-year history of wind-work on ocean inertial motions, Geophys. Res. Lett., 30(8), 1424, doi:10.1029/2002GL016614.

Anderson, D. L. T., and A. E. Gill (1979), Beta dispersion of inertial waves, J. Geophys. Res., 84(C4), 1836-1842.

Danioux, E., and P. Klein (2007), A resonance mechanism leading to wind-forced motions with a $2 f$ frequency, J. Phys. Oceanogr., submitted.

Danioux, E., P. Klein, and P. Rivière (2007), Propagation of wind energy into the deep ocean through mesoscale eddies, J. Phys. Oceanogr., submitted.

D’Asaro, E. A., C. C. Eriksen, M. D. Levine, P. Niiler, C. A. Paulson, and P. Van Meurs (1995), Upper-ocean inertial currents forced by a strong storm. Part I: Data and comparisons with linear theory, J. Phys. Oceanogr., 25(11), 2909-2936.

Enomoto, T., A. Kuwano-Yoshida, N. Komori, and W. Ohfuchi (2007), Description of AFES 2: Improvements for high-resolution and coupled simulations, in High Resolution Numerical Modelling of the Atmosphere and Ocean, edited by K. Hamilton and W. Ohfuchi, chap. 5, pp. 77-98, Springer. 
Garrett, C. (2001), What is the "near-inertial" band and why is it different from the rest of the internal wave spectrum?, J. Phys. Oceanogr., 31(4), 962-971.

Klein, P. (2007), High-frequency winds and eddy resolving models, in Eddy-Resolving Ocean Modeling, edited by M. Hecht and H. Hasumi, AGU Monograph, American Geophysical Union, in press.

Klein, P., G. Lapeyre, and W. G. Large (2004), Wind ringing of the ocean in presence of mesoscale eddies, Geophys. Res. Lett., 31(15), L15306, doi:10.1029/2004GL020274.

Komori, N., K. Takahashi, K. Komine, T. Motoi, X. Zhang, and G. Sagawa (2005), Description of sea-ice component of Coupled Ocean-Sea-Ice Model for the Earth Simulator (OIFES), J. Earth Simulator, 4, 31-45.

Komori, N., A. Kuwano-Yoshida, T. Enomoto, H. Sasaki, and W. Ohfuchi (2007), Highresolution simulation of the global coupled atmosphere-ocean system: Description and preliminary outcomes of CFES (CGCM for the Earth Simulator), in High Resolution Numerical Modelling of the Atmosphere and Ocean, edited by K. Hamilton and W. Ohfuchi, chap. 14, pp. 241-260, Springer.

Kunze, E. (1985), Near-inertial wave propagation in geostrophic shear, J. Phys. Oceanogr., 15(5), 544-565.

Large, W. G., J. C. McWilliams, and S. C. Doney (1994), Oceanic vertical mixing: A review and a model with a nonlocal boundary layer parameterization, Rev. Geophys., 32(4), 363-404.

Masumoto, Y., et al. (2004), A fifty-year eddy-resolving simulation of the world oceanPreliminary outcomes of OFES (OGCM for the Earth Simulator), J. Earth Simulator, 1, $35-56$. 
Mori, K., T. Matsuno, and T. Senjyu (2005), Seasonal/spatial variations of the near-inertial oscillations in the deep water of the Japan Sea, J. Oceanogr., 61(4), 761-773.

Munk, W., and C. Wunsch (1998), Abyssal recipes II: Energetics of tidal and wind mixing, Deep-Sea Res., 45(12), 1977-2010.

Nagasawa, M., Y. Niwa, and T. Hibiya (2000), Spatial and temporal distribution of the windinduced internal wave energy available for deep water mixing in the North Pacific, J. Geophys. Res., 105(C6), 13,933-13,943.

Niwa, Y., and T. Hibiya (1997), Nonlinear processes of energy transfer from traveling hurricanes to the deep ocean internal wave field, J. Geophys. Res., 102(C6), 12,469-12,478.

Niwa, Y., and T. Hibiya (1999), Response of the deep ocean internal wave field to traveling midlatitude storms as observed in long-term current measurements, J. Geophys. Res., 104(C5), $10,981-10,990$.

Ohfuchi, W., et al. (2004), 10-km mesh meso-scale resolving simulations of the global atmosphere on the Earth Simulator-Preliminary outcomes of AFES (AGCM for the Earth Simulator), J. Earth Simulator, 1, 8-34.

Pacanowski, R. C., and S. M. Griffies (1999), The MOM3 manual, GFDL Ocean Group Technical Report 4, NOAA/Geophysical Fluid Dynamics Laboratory, Princeton, NJ.

Price, J. F. (1983), Internal wave wake of a moving storm. Part I. Scales, energy budget and observations, J. Phys. Oceanogr., 13(6), 949-965.

Tsujino, H., H. Hasumi, and N. Suginohara (2000), Deep pacific circulation controlled by vertical diffusivity at the lower thermocline depths, J. Phys. Oceanogr., 30(11), 2853-2865. 
Watanabe, M., and T. Hibiya (2002), Global estimates of the wind-induced energy flux to inertial motions in the surface mixed layer, Geophys. Res. Lett., 29(8), 1239, doi: 10.1029/2001GL014422.

Wunsch, C., and R. Ferrari (2004), Vertical mixing, energy and the general circulation of the ocean, Annual Rev. Fluid Mech., 36, 281-314.

Zhai, X., R. J. Greatbatch, and C. Eden (2007), Spreading of near-inertial energy in a 1/12 ${ }^{\circ}$ model of the North Atlantic Ocean, Geophys. Res. Lett., 34(10), L10609, doi: 10.1029/2007GL029895. 

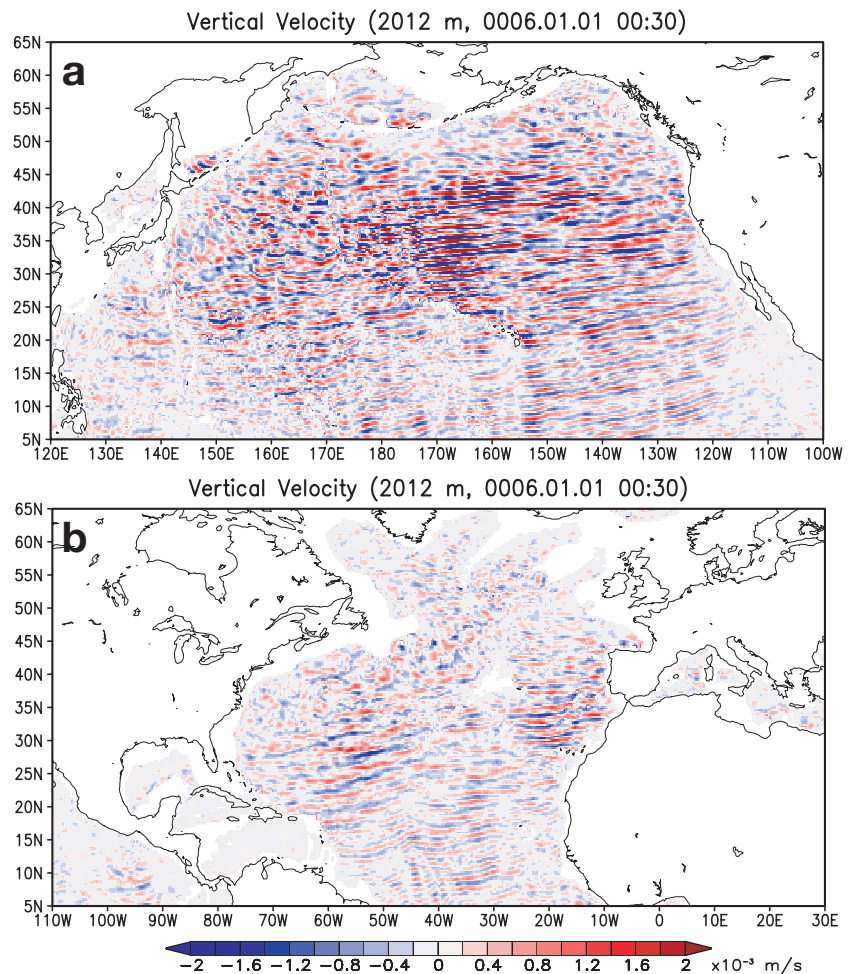

Figure 1. Snapshots of vertical velocity at 2012-m depth (a) in the North Pacific and (b) in the North Atlantic. Unit in color bar is $10^{-3} \mathrm{~m} \mathrm{~s}^{-1}$. 


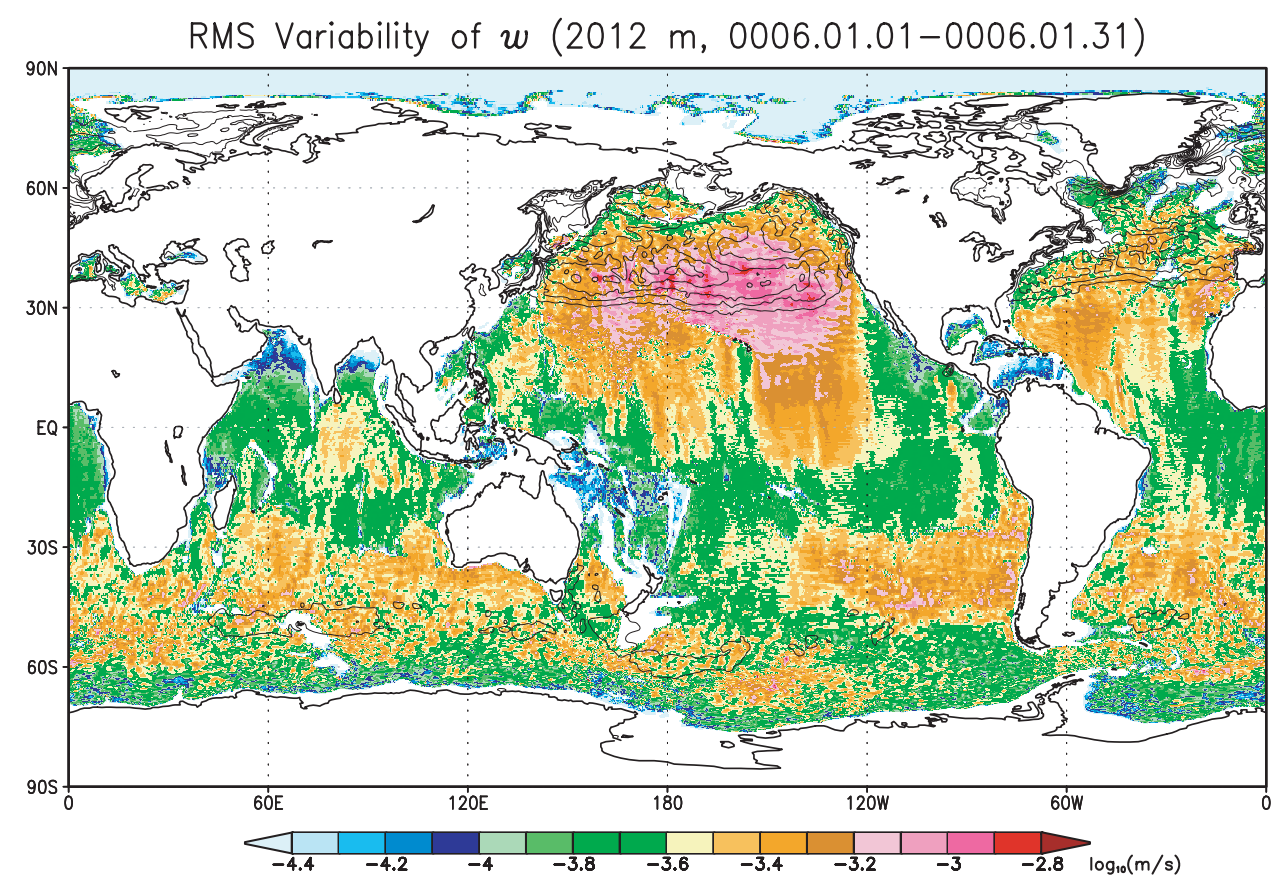

Figure 2. RMS variability of vertical velocity calculated from one month data at 2012-m depth.

Unit in color bar is common logarithm of $\mathrm{m} \mathrm{s}^{-1}$. Overplotted are RMS variability of the surface stress magnitude $\left(\geq 0.2 \mathrm{~N} \mathrm{~m}^{-2}\right)$. Contour interval is $0.05 \mathrm{~N} \mathrm{~m}^{-2}$. 

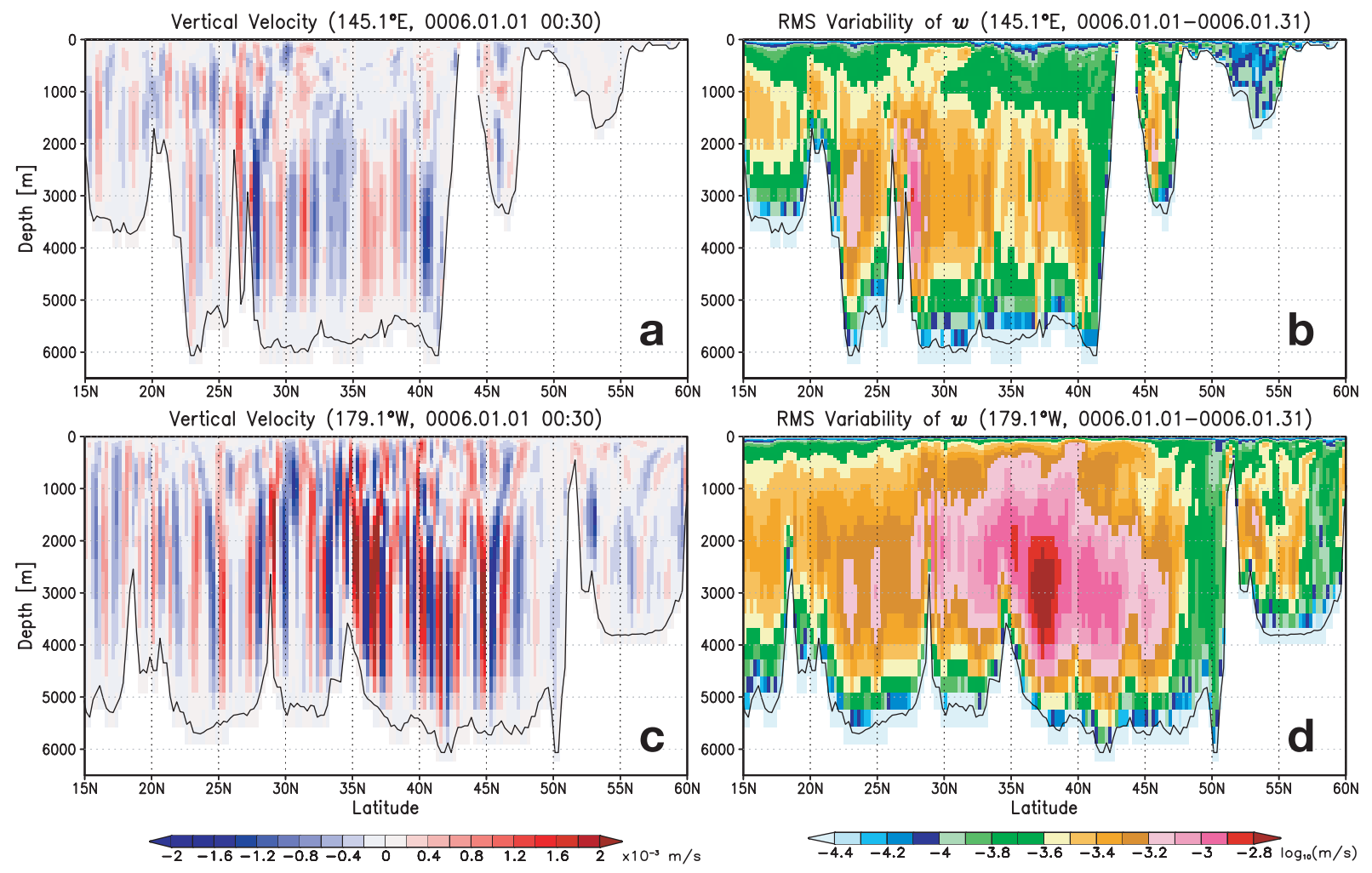

Figure 3. (left) Snapshots and (right) RMS variability of vertical velocity along (top) $145.1^{\circ} \mathrm{E}$ and (bottom) $179.1^{\circ} \mathrm{W}$. Units in color bars are $10^{-3} \mathrm{~m} \mathrm{~s}^{-1}$ for snapshots and common logarithm of $\mathrm{m} \mathrm{s}^{-1}$ for RMS variability. RMS variability is calculated from one month data. 

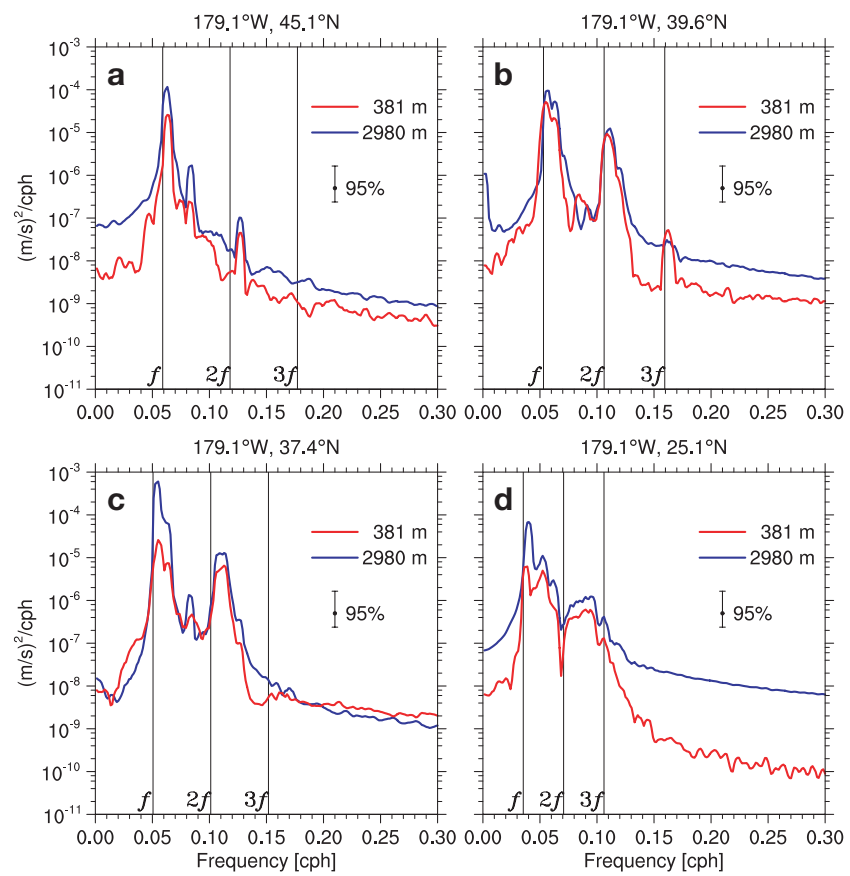

Figure 4. Frequency spectrum of vertical velocity calculated from one month data along $179.1^{\circ} \mathrm{W}$ at the depths of $381 \mathrm{~m}$ (red curve) and $2980 \mathrm{~m}$ (blue curve). (a) $45.1^{\circ} \mathrm{N}$, (b) $39.6^{\circ} \mathrm{N}$, (c) $37.4^{\circ} \mathrm{N}$, and (d) $25.1^{\circ} \mathrm{N} . f$ is the local inertial frequency. 